\title{
Female Sex Seems to be A Favorable Factor in COVID-19 Era
}

\author{
Alessia Gambaro, Borejda Xhyheri ${ }^{1}$, Yasmin Rustamova ${ }^{2}$, Nihan Caglar ${ }^{3}$ \\ ORCID: \\ Alessia Gambaro: https://orcid.org/0000-0001-8341-1427 \\ Borejda Xhyheri: https://orcid.org/0000-0001-9434-0097 \\ Yasmin Rustamova: https://orcid.org/0000-0002-5197-1945 \\ Nihan Caglar: https://orcid.org/0000-0001-7925-2398
}

Department of Cardiology, AOUI, University of Verona, Verona, ${ }^{1}$ Department of Cardiology, Nuovo Ospedale Degli Infermi, Biella, Italy, ${ }^{2}$ Department of Internal Medicine, Azerbaijan Medical University, Baku, Azerbaijan, ${ }^{3}$ Department of Cardiology, Bakirkoy Dr Sadi Konuk Training and Research Hospital, Istanbul, Turkey

\section{Abstract}

Coronavirus disease-2019 (COVID-19) is a novel disease that has become a global health problem with high mortality rates. Up to now, there is neither specific treatment nor a vaccine for the disease; hence, the primary goal is to keep patients alive. There is growing evidence that more men than women are dying from the COVID-19. Although the outbreak of COVID-19 has led to the legislation of exceptional public health measures in various countries, fatality difference among genders has not been changed in favor of women. It is important to understand the role of sex to figure out who is most vulnerable to COVID-19 and the risk factors of death. While the precise mechanism of globally observed lower female death rates is still unknown, there are many speculations such as the effect of X chromosome, immunologic distinction, lifestyle choices, and employment status. The aim of this review is to highlight the most relevant connections between COVID-19 and low mortality rate in women globally.

Keywords: COVID-19, female sex, infectious diseases

\section{INTRODUCTION}

A novel coronavirus was recognized as the reason of a group of pneumonia cases of unidentified etiology in Wuhan, China, at the end of December 2019, hence named as coronavirus disease-2019 (COVID-19). ${ }^{[1]}$ COVID-19 has quickly become widespread, resulting in a pandemic, affecting millions of people worldwide. ${ }^{[1,2]}$ Meanwhile, an interesting fact was observed and described first in Wuhan. ${ }^{[2]}$ Infection has been detected more in men than woman (about $60 \%$ of infected were men). ${ }^{[1,2]}$ Besides, death rate and severe course of disease observed more in men than women $(2.8 \%$ death rate for men vs. $1.7 \%$ for female). ${ }^{[1,2]}$ Not only China but also other countries repeated the Chinese experience; for instance, $58 \%$ of COVID-19-infected patients as well as $70 \%$ of infection-related deaths were observed in men in Italy. ${ }^{[3]}$

Received: 16-06-2020 Revised: 11-08-2020 Accepted: 05-10-2020

Published Online: 27-11-2020

\begin{tabular}{|l|l|}
\hline \multicolumn{3}{|c|}{ Access this article online } \\
\hline Quick Response Code: & Website: \\
& \\
http://www.ijcva.com
\end{tabular}

There are numerous observations of gender differences in different infectious diseases' course in the literature. ${ }^{[4,5]}$ Moreover, the data from recent coronavirus epidemics - severe acute respiratory syndrome (SARS, 2003) and Middle East respiratory syndrome (MERS, 2012) - demonstrated a sex susceptibility (mortality in males $21.9 \%$ vs. females $13.2 \%$ ). ${ }^{[6,7]}$

Although the underlying mechanism of this phenomenon is still unknown, factors such as, the effect of $\mathrm{X}$ chromosome, immunologic distinction, lifestyle choices, and employment status are mostly associated with lower female mortality [Figure 1]. The aim of this review is to highlight the most relevant connections between COVID-19 and low mortality rate in women globally.

Address for correspondence: Dr. Nihan Caglar, Department of Cardiology, Bakirkoy Dr Sadi Konuk Training and Research Hospital, Istanbul, Turkey. E-mail: nhnturhan@gmail.com

This is an open access journal, and articles are distributed under the terms of the Creative Commons Attribution-NonCommercial-ShareAlike 4.0 License, which allows others to remix, tweak, and build upon the work non-commercially, as long as appropriate credit is given and the new creations are licensed under the identical terms.

For reprints contact: WKHLRPMedknow_reprints@wolterskluwer.com

How to cite this article: Gambaro A, Xhyheri B, Rustamova Y, Caglar N. Female sex seems to be a favorable factor in COVID-19 era. Int J Cardiovasc Acad 2020;6:143-6. 


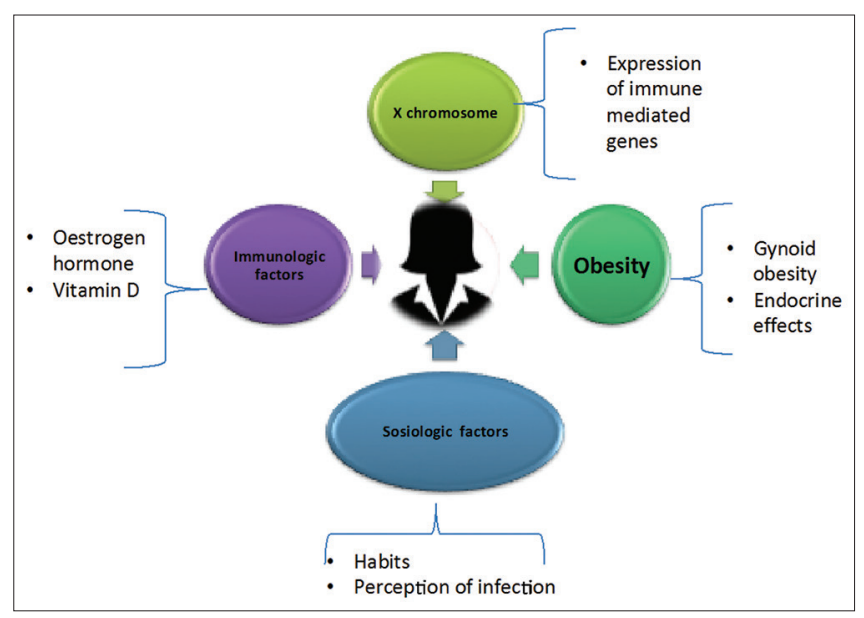

Figure 1: Factors associated with low female mortality

\section{The Effect of X Chromosome}

The X chromosome translates most immune-mediated genes in the human genome which could be an explanation of higher female immune response. ${ }^{[8]}$ Angiotensin-converting enzyme 2 (ACE2) and its role in viral transmission are one of the most discussable points in the current COVID-19-related literature. ${ }^{[9,10]}$ An interesting explanation of the influence of $\mathrm{X}$ chromosome and hormones in the severity of COVID-19 is proposed by Foresta et al..$^{[11]}$ According to recent findings, ACE2 binds the viral spike protein, this allows transmembrane serine protease-2 (TMPRSS2) to prime S protein. ${ }^{[1]}$ This favors viral infection of human alveolar epithelial cells. There is a difference in ACE2, TMPRSS2, and ACE expression in males and females. ${ }^{[12]} \mathrm{ACE} 2$ is particularly important in tissue response to viral infection because it converts angiotensin I into angiotensin 1-7, which binds to Mas receptor (MasR). ${ }^{[12]}$ MasR has a protective role in promoting hypotensive and anti-infammatory pathways. ${ }^{[12]}$ Conversely, ACE converts angiotensin I into angiotensin II/III which causes tissue injury, by binding angiotensin II Type 1 receptor. ACE2 expression is higher in women because its gene is located on the $\mathrm{X}$ chromosome (two copies) and estrogens promote ACE2 expression. ${ }^{[13]}$ In males, there are lower ACE2 levels compared to women because they have just one copy of ACE2 gene and lower estrogens production. ${ }^{[9,10]}$ The low ACE2 pool in men favors the ACE pathway which causes tissue injury. ${ }^{[9,10]}$

Another enzyme that plays a key role in the penetration, spread and replication of the SARS-Cov-2 virus in the human body and which is responsible for the second step of virus penetration, is TMPRSS2, which is encoded by the TMPRSS2 gene. ${ }^{[14]}$ TMPRSS2 is also crucial for viral activation and cell entry not only in COVID-19 but also in other types of coronaviruses and influenza viruses, such as SARS-CoV and H1N1. ${ }^{[15]}$ TMPRSS2 gene expression was firstly cloned and marked in prostate cancer. ${ }^{[16]}$ Moreover, it is known that TMPRSS2 related androgen expression regulates the prostat cancer cells. ${ }^{[17]}$ The high appearance of TMPRSS2 in prostate cancer in addition to the robust association with androgens brings up to the idea of the potential role of this protease in the COVID-19 outbreak. ${ }^{[17]}$

TMPRSS2 is expressed in the lung, but also outside, that can facilitate the extrapulmonary viral dissemination into the whole body. ${ }^{[18]}$ Some small immunohistochemistry studies put forward the idea that this protein is present more in bronchial epithelial cells than in surfactant producing type II alveolar cells and alveolar macrophages. ${ }^{[18]}$

Different factors of TMRPSS2 protein expression in the lung could align with risk factors of TMRPSS2 fusion-positive prostate cancer and might be useful to be investigated in terms of risk reduction of respiratory infection. ${ }^{[17,18]}$

Furthermore, the promoter of TMPRSS2 has androgen-responsive elements. ${ }^{[11]}$ This leads to increased expression of TMPRSS2 in males. ${ }^{[11]}$ These could be the explanation why with the same viral load, men experience more severe tissue damage, compared to women. ${ }^{[11]}$

\section{The Effect of Immunology}

The initial pathogenesis of the SARS is due to the COVID-19 viral infection; however, an excessive and aggressive inflammatory response is the key factor of survival in severe cases. ${ }^{[19,20]}$ Hence, one of the possible explanation for gender different predisposition relies on immunologic system and the influence of hormones on the immunological factors. ${ }^{[1,22]}$ Estrogen (E2)/progesterone (P4) appeared to have a pivotal role in immunomodulation and protection from the development of COVID-19 disease. ${ }^{[21]}$ This is supported by the knowledge achieved with SARS-CoV2 predecessors (SARS-CoV and MERS-CoV). A translational research on a SARS-CoV-infected mice model demonstrated that male mice were more keen on developing severe infection, and their mortality rate was higher compared to female mice. ${ }^{[22]}$ Examination of the male infected mice lungs showed more severe hyperemia and vascular leakage. This was consequent to an excessive inflammatory and cytokine innate response. ${ }^{[22]}$ Estrogens or estrogen-receptor agonist/modulator had a protective function on female mice; indeed, ovariectomy resulted in increased mortality. Conversely, androgen did not show any influence on the disease outcome. ${ }^{[22]}$ These findings were consistent with another research which detected where influenza A virus replication was decreased in human nasal epithelial cells by estrogen-receptor-2 agonists/modulators. ${ }^{[23]}$

Eestrogens receptors are expressed in all immune cells (CD4+ T lymphocytes, CD8+ T cells, monocytes, and B lymphocytes. ${ }^{[24]}$ Experiments on human models and mice demonstrated that estrogens suppress the production of interleukin (IL)-6, IL-1 $\beta$, IL-17 and tumor necrosis factor (highly pro-inflammatory cytokines) and decrease migrations of immune cells into the inflamed area. Furthermore, estrogens increase the production of anti-inflammatory cytokines by $\mathrm{CD} 4+$ helper and promote immune tolerance by $\mathrm{T}$ regulatory cells. ${ }^{[24]}$

A similar immunomodulatory and anti-inflammatory hormone is produced by progesterone $(\mathrm{P} 4){ }^{[25,26]}$ Progesterone is able to reduce 
the production of pro-inflammatory IL-1 $\beta$ and IL-12 cytokines and favors the CD4+ Th2-type cell, which has anti-inflammatory effect. ${ }^{[25,26]}$ Furthermore, estrogens favor the production of antibodies (Abs) by B-cells. ${ }^{[25,26]}$ On the base of the effectiveness of serum of convalescent patients in SARS-CoV2-infected patients, it seems that Abs have an important role in the neutralization of the virus. ${ }^{[25,26]}$

Another interesting aspect which could explain the sex difference in the severity of COVID-19 is related to Vitamin Ds affect on the immunological system. ${ }^{[27,28]}$ In the translational model, Vitamin D was able to decrease influenza A and rotavirus replication. ${ }^{[29]}$ Although it has not been proven in case of COVID-19, it is possible that supplementation of Vitamin D, quite common in female old patients, can exert a protective effect like the one in case of respiratory syncytial virus-infection. ${ }^{[30]}$

\section{The Effect of Demographic and Sociological FACTORS}

Although sex and gender are often used synonymously, they imply profound differences in the meaning. ${ }^{[31]}$ Sex refers to the pure biological determinants of an individual, while gender refers to the sum of social roles, education, behaviors, and activities that are considered appropriate for men and women in any given society. ${ }^{[31]}$ Thus, when analyzing the striking difference in mortality between male and female affected by COVID-19, the possible explanations seem to go beyond the simple biological differences.

Italian pilot data of patients with severe COVID-19 disease show strong associations with existing comorbidities such as hypertension, cardiovascular disease and chronic lung diseases. ${ }^{[32]}$ The presence of cardiovascular diseases increases overall patients' fragility and in the COVID-19 setting has been observed to enhance the risk of death. ${ }^{[32]}$ Coherently, the higher incidence in male population of heart and lung disease to a certain extent can be explained by to the gendered behaviors. For example, rates of smoking tobacco and drinking alcohol are all substantially higher in men than women. ${ }^{[32]}$ These behaviors on the one hand increase the risk of developing comorbidities associated with adverse outcomes in COVID-19, and on the other hand, they reflect some gender-based customs that may expose male population to a higher risk of COVID-19 clinical worse expression. ${ }^{[32]}$

About $50 \%$ of men in China smoke compared to $2 \%$ of women. ${ }^{[33]}$ Preliminary data suggest that smoking is associated with adverse outcomes of COVID-19, specifically a higher risk of being admitted to the intensive care unit, need for mechanical ventilation, and death. ${ }^{[34]}$ Although the difference of smoking among genders is not that striking in some western European countries, such as Germany and Spain, ${ }^{[35]}$ it still remains in the overall global population and may partially explain the excess of male Covid-19 mortality, ${ }^{[35]}$ especially when considering its exponential effects taken together with the other risks factors exposing man to a higher risk of COVID-19 mortality. ${ }^{[35]}$
One of the other gender-based drivers as possible explanations for gender gap in COVID-19 mortality is men's general lower perception of dangerous situations, their lower attitude of feeling disease's symptoms, and in turn not seeking medical attention on time. ${ }^{[36]}$ Besides, a meta-analysis conducted in 2016 showed that women are about 50\% more likely than men to use nonpharmaceutical protective equipment during a pandemic, such as wearing face masks, using soap for handwashing, and avoiding public transport. ${ }^{[37]}$ Similarly, a survey conducted between March 2 and 13 found that women were more concerned about COVID-19 than men (62\% vs. $58 \%) .{ }^{[38]}$ This suggests that deliberate observance of health measures, such as social distancing during the COVID-19 pandemic, may be at least lower among men. ${ }^{[38]}$

\section{The Effect OF Obesity}

Obesity is another factor of COVID-19-related mortality. ${ }^{[39]}$ In a study of roughly 17,000 UK inhospital patients with COVID-19, male population requiring hospital admission was significantly higher $(60.2 \%$ vs. $39.8 \%)$ and patients who were obese, with a body mass index (BMI) of more than 30, had a 33\% greater risk of death than those who were not obese. ${ }^{[39]}$ Nevertheless, international rates of obesity are higher in women than in men, and interestingly, severe obesity (BMI $\geq 40$ ) impacts life expectancy more in men than in women, by a reduction of as much as 20 years in men and by about 5 years in women. ${ }^{[40]}$ The greater reduction in life expectancy for men seems to be consistent with the pattern of fat distribution. ${ }^{[41]}$ These differences between the two patterns of obesity include anatomical, physiological, molecular, clinical, and prognostic outcomes with visceral adipose tissue being more prone to production of inflammatory and immune cells, compared to subcutaneous adipose tissue. ${ }^{[41]}$ Moreover, android obesity has a more direct effect on pulmonary mechanics than gynoid obesity and is strongly related to worse metabolic and clinical consequences of obesity. ${ }^{[42]}$ In addition to the endocrine effects, android obesity may enhance COVID-19 mortality through its detrimental effects on lung capacity, namely by decreasing lung and chest wall compliance and possibly contributing to the respiratory symptoms of obesity such as wheezing, dyspnea, and orthopnea. ${ }^{[33]}$

\section{ConcLusion}

The novel COVID-19 pandemic creates an enormous health burden globally. Although men and women are equally likely to contact COVID-19, men are significantly more prone to suffer from severe consequences of the disease. ${ }^{[1]}$ As the data from all over the world enhance, the underlying unique pathophysiological mechanisms of the disease's different course among genders will hopefully be explored.

\section{Financial support and sponsorship}

Nil.

\section{Conflicts of interest}

There are no conflicts of interest. 


\section{References}

1. Mo P, Xing Y, Xiao Y, Deng L, Zhao Q, Wang H, et al. Clinical characteristics of refractory COVID-19 pneumonia in Wuhan, China. Clin Infect Dis 2020:ciaa270. doi: 10.1093/cid/ciaa270. Epub ahead of print. PMID: 32173725; PMCID: PMC7184444..

2. Chen N, Zhou M, Dong X, Qu J, Gong F, Han Y, et al. Epidemiological and clinical characteristics of 99 cases of 2019 novel coronavirus pneumonia in Wuhan, China: A descriptive study. Lancet 2020;395:507-13.

3. Remuzzi A, Remuzzi G. COVID-19 and Italy: What next? Lancet 2020;395:1225-8.

4. Guan WJ, Ni ZY, Hu Y, Liang WH, Ou CQ, He JX, et al. Clinical characteristics of coronavirus disease 2019 in China. N Engl J Med 2020;382:1708-20.

5. Verma R, Balhara YP, Gupta CS. Gender differences in stress response: Role of developmental and biological determinants. Ind Psychiatry J 2011;20:4-10.

6. Channappanavar R, Fett C, Mack M, Ten Eyck PP, Meyerholz DK, Perlman S. Sex-based differences in susceptibility to severe acute respiratory syndrome coronavirus infection. J Immunol 2017; 198:4046-53.

7. Matsuyama R, Nishiura H, Kutsuna S, Hayakawa K, Ohmagari N. Clinical determinants of the severity of Middle East respiratory syndrome (MERS): A systematic review and meta-analysis. BMC Public Health 2016;16:1203.

8. Schurz H, Salie M, Tromp G, Hoal EG, Kinnear CJ, Möller M, et al. The $\mathrm{X}$ chromosome and sexspecific effects in infectious disease susceptibility. Hum Genomics 2019;13:2.

9. World Health Organization. Coronavirus Disease (COVID-19) Outbreak. http://www.who.int/emergencies/diseases/novel-coronavirus-2019/ events-as-they-happen. [Last accessed on 2020 Jan 10].

10. Patel SK, Velkoska E, Freeman M, Wai B, Lancefield TF, Burrell LM. From gene to protein-experimental and clinical studies of ACE2 in blood pressure control and arterial hypertension. Front Physiol 2014;5:227.

11. Foresta C, Rocca MS, Di Nisio A. Gender susceptibility to COVID-19: A review of the putative role of sex hormones and $\mathrm{X}$ chromosome [published online ahead of print, 2020 Sep 16]. J Endocrinol Invest 2020;16:1-6.

12. Hoffmann M, Kleine-Weber H, Schroeder S, Krüger N, Herrler T, Erichsen S, et al. SARSCoV-2 cell entry depends on ACE2 and TMPRSS 2 and is blocked by a clinically proven protease inhibitor. Cell 2020;181:271-280.e8.

13. Li W, Moore MJ, Vasilieva N, Sui J, Wong SK, Berne MA, et al. Angiotensin-converting enzyme 2 is a functional receptor for the SARS coronavirus. Nature 2003;426:450-4.

14. Bertram S, Glowacka I, Blazejewska P, Soilleux E, Allen P, Danisch S, et al. TMPRSS2 and TMPRSS4 facilitate trypsin-independent spread of influenza virus in Caco-2 cells. J Virol 2010;84:10016-25.

15. Chaipan C, Kobasa D, Bertram S, Glowacka I, Steffen I, Tsegaye TS, et al. Proteolytic activation of the 1918 influenza virus hemagglutinin. J Virol 2009;83:3200-11.

16. Lin B, Ferguson C, White JT, Wang S, Vessella R, True LD, et al. Prostate-localized and androgen-regulated expression of the membrane-bound serine protease TMPRSS2. Cancer Res 1999;59:4180-4.

17. Yoo S, Pettersson A, Jordahl KM, Lis RT, Lindstrom S, Meisner A, et al. Androgen receptor CAG repeat polymorphism and risk of TMPRSS2:ERG-positive prostate cancer. Cancer Epidemiol Biomarkers Prev 2014;23:2027-31.

18. Bertram S, Heurich A, Lavender H, Gierer S, Danisch S, Perin P, et al. Influenza and SARS-coronavirus activating proteases TMPRSS2 and HAT are expressed at multiple sites in human respiratory and gastrointestinal tracts. PLoS One 2012;7:e35876.

19. Tay MZ, Poh CM, Rénia L, MacAry PA, Ng LFP. The trinity of COVID-19: İmmunity, inflammation and intervention. Nat Rev Immunol 2020;20:363-74.

20. Karlberg J, Chong DS, Lai WY. Do men have a higher case fatality rate of severe acute respiratory syndrome than women do? Am J Epidemiol 2004;159:229-31.

21. Alghamdi IG, Hussain II, Almalki SS, Alghamdi MS, Alghamdi MM, El-Sheemy MA. The pattern of Middle East respiratory syndrome coronavirus in Saudi Arabia: A descriptive epidemiological analysis of data from the Saudi Ministry of Health. Int J Gen Med 2014;7:417-23.

22. Channappanavar R, Fett C, Mack M, Ten Eyck PP, Meyerholz DK,
Perlman S. Sex-based differences in susceptibility to severe acute respiratory syndrome coronavirus infection. J Immunol 2017;198:4046-53.

23. Peretz J, Pekosz A, Lane AP, Klein SL. Estrogenic compounds reduce influenza A virus replication in primary human nasal epithelial cells derived from female, but not male, donors. Am J Physiol Lung Cell Mol Physiol 2016;310:L415-25.

24. Straub RH. The complex role of estrogens in inflammation. Endocr Rev 2007;28:521-74.

25. PiccinniMP,GiudiziMG,BiagiottiR,BeloniL, GiannariniL, SampognaroS, et al. Progesterone favors the development of human $\mathrm{T}$ helper cells producing Th2-type cytokines and promotes both IL-4 production and membrane CD30 expression in established Th1 cell clones. J Immunol 1995; 155:128-33.

26. Szekeres-Bartho J, Wegmann TG. A progesterone-dependent immunomodulatory protein alters the Th1/Th2 balance. J Reprod Immunol 1996;31:81-95.

27. Gombart AF, Pierre A, Maggini S. A review of micronutrients and the immune system-working in harmony to reduce the risk of infection. Nutrients 2020;12:236.

28. Schwalfenberg GK. A review of the critical role of Vitamin D in the functioning of the immune system and the clinical implications of Vitamin D deficiency. Mol Nutr Food Res 2011;55:96-108.

29. Zhao Y, Ran Z, Jiang Q, Hu N, Yu B, Zhu L, et al. Vitamin D alleviates rotavirus infection through a microrna-155-5p mediated regulation of the TBK1/IRF3 signaling pathway in vivo and in vitro. Int J Mol Sci 2019;20:3562.

30. Hansdottir S, Monick M, Lovan N, Powers L, Gerke A, Hunninghake G. Vitamin D decreases respiratory syncytial virus induction of NF-kappaB-linked chemokines and cytokines in airway epithelium while maintaining the antiviral state. J Immunol 2010;184:965-74.

31. Crimmins EM, Shim H, Zhang YS, Kim JK. Differences between men and women in mortality and the health dimensions of the morbidity process. Clin Chem 2019;65:135-45.

32. Guan WJ, Ni ZY, Hu Y, Liang WH, Ou CQ, He JX, et al. China medical treatment expert group for Covid-19. clinical characteristics of coronavirus disease 2019 in China. N Engl J Med 2020;382:1708-20.

33. Liu S, Zhang M, Yang L, Li Y, Wang L, Huang Z, et al. Prevalence and patterns of tobacco smoking among Chinese adult men and women: Findings of the 2010 national smoking survey. J Epidemiol Community Health 2017;71:154-61.

34. Vardavas CI, Nikitara K. COVID-19 and smoking: A systematic review of the evidence. Tob Induc Dis 2020;18:20.

35. Zhang JJ, Dong X, Cao YY, Yuan YD, Yang YB, Yan YQ, et al. Clinical characteristics of 140 patients infected with SARS-CoV-2 in Wuhan, China. Allergy 2020;75:1730-41.

36. Springer KW, Mager Stellman J, Jordan-Young RM. Beyond a catalogue of differences: A theoretical frame and good practice guidelines for researching sex/gender in human health. Soc Sci Med 2012;74:1817-24.

37. Moran KR, Del Valle SY. A meta-analysis of the association between gender and protective behaviors in response to respiratory epidemics and pandemics. PLoS One 2016;11:e0164541.

38. Jin JM, Bai P, He W, Wu F, Liu XF, Han DM, et al. Gender differences in patients with COVID-19: Focus on severity and mortality. Front Public Health 2020;8:152.

39. Docherty AB, Harrison EM, Green CA, Hardwick HE, Pius R, Norman L, et al. Features of 16,749 hospitalised UK patients with COVID-19 using the ISARIC WHO Clinical Characterisation Protocol. medRxiv 2020.04.23.20076042; doi: https://doi.org/10.1101/2020.04.23.20076042

40. Finucane MM, Stevens GA, Cowan MJ, Danaei G, Lin JK, Paciorek CJ, et al. National, regional, and global trends in body-mass index since 1980: Systematic analysis of health examination surveys and epidemiological studies with 960 country-years and $9 \cdot 1$ million participants. Lancet 2011;377:557-67.

41. Pi-Sunyer FX. The epidemiology of central fat distribution in relation to disease. Nutr Rev 2004;62:S120-6.

42. Pelosi P, Croci M, Ravagnan I, Tredici S, Pedoto A, Lissoni A, et al. The effects of body mass on lung volumes, respiratory mechanics, and gas exchange during general anesthesia. Anesth Analg 1998;87:654-60.

43. Dixon AE, Peters U. The effect of obesity on lung function. Expert Rev Respir Med 2018;12:755-67. 